\section{By the Numbers}

\section{Weather and Climate Go Together}

\author{
Katrina Stierholz
}

W hich government information webpages are used most frequently? Does it surprise you that weather pages are used more than any other government information pages? (For details on the pages used, see Campbell's column on the Digital Analytics Program in the previous issue of $B T N$ ). The weather. gov domain had over 14 million visits in the past 7 days (when I checked). Every day, the weather is in the news: flash floods, tornadoes, rain, drought, snow, lightning, heat, hurricanes, and cold. Intense weather can be hazardous and costly: Every year people lose their lives and their property to weather events. This column focuses on weather and climate data sources that can help people become "weather-ready and climate-smart" in terms of making their businesses and communities resilient to extreme events.

Collecting weather data has a long history in the United States. The weather interests of Thomas Jefferson and Benjamin Franklin are examples of early efforts to collect weather information from across the United States. Weather information was collected and distributed to support and protect shipping, the military, farming, and fisheries. In 1870, President Ulysses S. Grant established a formal weather office. Initially located in the War Department (1870-90), the weather service was later moved to Agriculture (1890-1940) and finally into the Commerce Department, under the National Oceanic and Atmospheric Administration (NOAA). These historical parent agencies reflect the importance of weather to various constituencies. NOAA and the National Weather Service (NWS) are assigned the $\mathrm{C} 55 \mathrm{SuDoc}$ classification.

Weather data collected over a long period and aggregated into long-term averages of atmospheric conditions determine the range of what is considered a "normal" climate for a particular place and time of year, and in turn, become climate data. As science and industry focus on the effects of climate change, climate data are vital to planning and understanding the impact of a changed climate on people and property.

\section{Weather Data (quick answer: weather.gov)}

The NWS is responsible for producing weather forecasts and measuring weather in the United States. The NWS has 122 field offices throughout the United States and produces over 76 billion observations each year. ${ }^{1}$ These regional offices are the source of most of our regular weather forecasts—we may read them

\section{Weather Acronym Helper}

CPC: Climate Prediction Center

NOAA: National Oceanic and Atmospheric Administration

NWS: National Weather Service (a department within

NOAA)

WFO: Weather Forecast Office

online from the local office or get them from news organizations or weather organizations that use the public domain data and forecasts made available by the NWS. These public domain data allow others to offer alternate forecasts.

Use weather.gov to locate current weather forecasts and data. In addition to its 122 field offices (list at www.srh.noaa .gov/jetstream/nws/wfos.htm), the NWS also has over 10,000 volunteer weather observation stations across the country that provide additional weather data. Over 290,000 trained severe weather spotters supplement those stations. Together these professionals and volunteers provide timely, accurate reporting on current weather conditions. In addition to collecting data on the weather as it happens, NWS meteorologists compile forecasts using current weather data and models. The forecasts are available as data, as maps, and as models. All of the information you need for a local forecast or local weather data collection is available at weather.gov (with the exception of weather data for lawsuits, which require certified data but can be retrieved from NOAA by request).

To access current forecast data for your local area, the best site is your local Weather Forecast Office (WFO), part of the network of 122 field offices. Use weather.gov as the starting point and your zip code as the location. From that point, each field office has a three-letter code assigned to it. I love weather and know that the local code for St. Louis is LSX (weather.gov/ lsx). Knowing the local code for your forecast office may be nearly as useful as learning the local code for your airport. For each forecast office website, expect to find current weather, local forecasts, historical data, and a forecast discussion describing uncertainty around the immediate forecast. Forecast discussions are particularly useful for understanding current conditions and the immediate future. Each forecast office has a slightly different selection of information, particularly in the climate section, as every area has its own unique weather patterns.

The NWS is also responsible for providing marine, ocean, and space weather in addition to aviation, hurricane, and hydrologic information. Through the NWS, you can locate forecasting and weather conditions for lakes, oceans, air, rivers, and the atmosphere as well as forecasts (think Perfect Storm). 


\section{By the Numbers}

\section{Climate Data (quick answer: climate.gov)}

Climate is the long-term pattern of weather in a particular area, usually based on a 30-year average. ${ }^{2}$ Climate data, including past weather conditions and long-term averages, are available in several places: your local WFO, the Climate Prediction Center's (CPC) data page, climate.gov, and the National Centers for Environmental Information. All of these organizations are part of NOAA; the first two are within the NWS. The website, climate.gov, is produced in NOAA's Office of Oceanic and Atmospheric Research Climate Program Office.

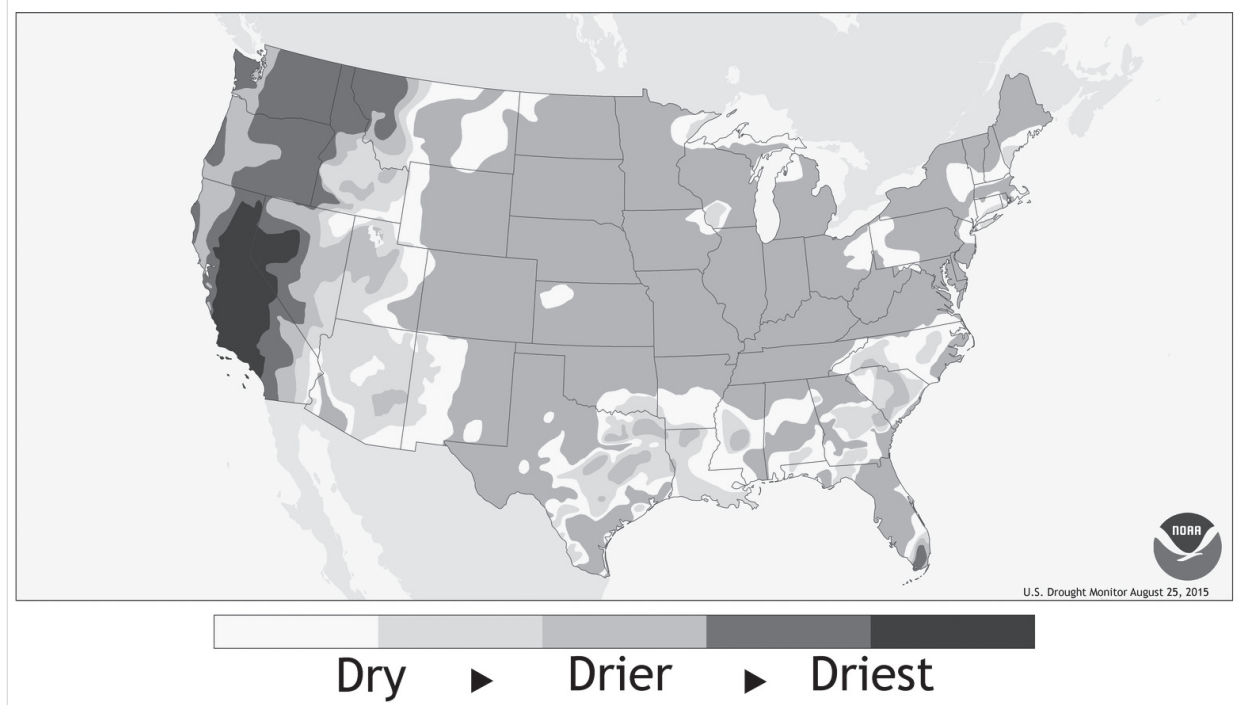

Drought map of the United States for May 3, 2016. https://www.climate.gov/maps-data/data-snapshots/ usdroughtmonitor-weekly-ndmc-2016-05-03?theme=Drought.
Climate is also more than the longterm average of weather. Earth's climate system provides the context in which weather happens - in other words, the state of the climate system influences the odds that certain types of weather are more or less likely to happen. NOAA leads and participates in research to advance understanding of how Earth's climate system works, where and why the climate system is changing, and the causes and effects of change.

Your local WFO provides preliminary local historical data and climate information for your area. To find these data, go to the "Climate" section of the forecast page for your WFO (weather.gov/xxx, or to access it directly, go to climate.gov/climate/index.php?wfo=xxx, where $\mathrm{xxx}$ is the WFO symbol). From this page, all the local data are available in a tab (typically called Local Data/Records). Monthly and seasonal temperatures are generally available and often provide over 100 years of data. In addition, many WFOs provide unique resources for their area. In other words, if your area has tornadoes, expect to find reports on the historical frequency and severity of tornadoes.

NOAA's Climate.gov is a public-friendly source of timely data and information about climate. The site provides four areas: (1) News \& Features is a popular-style online magazine for the public covering topics in climate science; (2) Maps \& Data provides terrific visualizations of weather data and the dataset gallery provides access to data and tools for visualizing those data (see image 1, the drought map of the United States for May 3, 2016); (3) Teaching Climate offers resources for educators, mapped to grade ranges and learning standards; and (4) the Climate Resilience Toolkit (toolkit.climate.gov) offers tools, information, and expertise to help people manage their climate-related risks and opportunities and improve their resilience to extreme events.

The third site for climate data and forecasts is the Climate Prediction Center (www.cpc.ncep.noaa.gov). The CPC provides weather outlooks for a series of time periods (weeks, months, and a season). The CPC releases hurricane outlooks and El Niño predictions. This Center is part of the National Centers for Environmental Prediction (www.ncep.noaa.gov/); the various centers within that group address climate and longrange prediction for the many types of weather that NOAA monitors. The CPC also provides links to comprehensive timeseries weather and climate data for research use.

Finally, for a comprehensive collection of climate data, the National Centers for Environmental Information (https://www .ncei.noaa.gov) offers over 20 petabytes of climate data for a wide range of climate-related observations and measurements that are well suited for both climate research and decision-making. This site offers a search by type of data, linking data from many different NOAA sources into a single place.

\section{Special Resources}

In addition to the NWS, a few other agencies provide specialized weather information and forecasts. The U.S. Department of Agriculture provides weekly weather and crop bulletins (www.usda.gov/oce/weather/) with agriculture-specific maps and information highlighting the weather risks to crops and commodity prices. The historical bulletins are available back to 1971 (perhaps a birthday gift—a bulletin from the week of your birth!). In addition, the Centers for Disease Control (CDC) (http://wonder.cdc.gov) provides weather-related data in terms 
of public health, such as measuring particulate matter, sunlight, and heat waves. It is easy to forget how much health is impacted by weather and climate; the CDC data are a handy reminder.

American's health, security, and economic well-being are closely linked to weather and climate. People want and need timely access to information and data to understand where and how weather conditions are changing and help them make decisions on how to manage risks and opportunities they face in their communities and businesses. In addition, librarians may find these resources a fresh way to present concepts and exercises in data literacy.

Katrina Stierholz (Katrina.L.Stierholz@stls.frb.org) is Director of Library and Research Information Services, Federal Reserve Bank of St. Louis. ${ }^{3}$

\section{References}

1. "About NOAA's National Weather Service," accessed July 26, 2015, www.weather.gov/about.

2. Analytics.usa.gov homepage, accessed May 11, 2016, https://analytics.usa.gov.

3. The views expressed in this column are those of the author and do not necessarily reflect the position of the Federal Reserve Bank of St. Louis or the Federal Reserve System. 